\title{
UNLV's Environmentally Friendly Science and Engineering Building is Monitored for Earthquake Shaking
}

\author{
The University of Nevada Las \\ Vegas' (UNLV) Science and \\ Engineering Building is at the \\ cutting edge of environmentally \\ friendly design. As the result of a \\ recent effort by the U.S. Geological \\ Survey's National Strong Motion \\ Project in cooperation with UNLV, \\ the building is now also in the \\ forefront of buildings installed with \\ structural monitoring systems to \\ measure response during earth- \\ quakes. This is particularly impor- \\ tant because this is the first such \\ building in Las Vegas. The seismic \\ instrumentation will provide essen- \\ tial data to better understand the \\ structural performance of build- \\ ings, especially in this seismically \\ active region.
}

Nevada is one of the Nation's most seismically active States, and a strong earthquake could cause significant damage in the heavily populated Las Vegas region. The region occupies a fault-bounded basin filled with alluvium (sediments deposited by flowing water) as much as 3 miles deep, making the region especially prone to earthquake shaking. Earthquake hazards are posed by major faults in neighboring Death Valley, California, and faults within and much closer to the basin, that are capable of generating seismic events of magnitude 7 or greater. The Science and Engineering Building at the University of Nevada Las Vegas (UNLV) campus was recently instrumented for earthquake monitoring by the U.S. Geological Survey's (USGS) National Strong Motion Project (NSMP) in cooperation with UNLV's Department of Civil and Environmental Engineering and Construction. This is the first building in Las Vegas furnished with sophisticated seismic instrumentation and advanced, real-time data processing systems to monitor its structural integrity. The monitoring system combines sensing technologies with automatic analysis software, capable of computing how earthquakes affect the structure, thus providing valuable information that can be used to judge the safety of the building after a seismic event and to design safer structures in the future.

The UNLV Science and Engineering Building is a steel-moment-frame structure with diagonal bracings and has been awarded a "Silver" rating by the Leadership in Energy and Environmental Design (LEED) program (http:// new.usgbc.org/leed). To obtain a LEED rating, a building must meet environmentally responsible and sustainable design, construction, and operation standards.

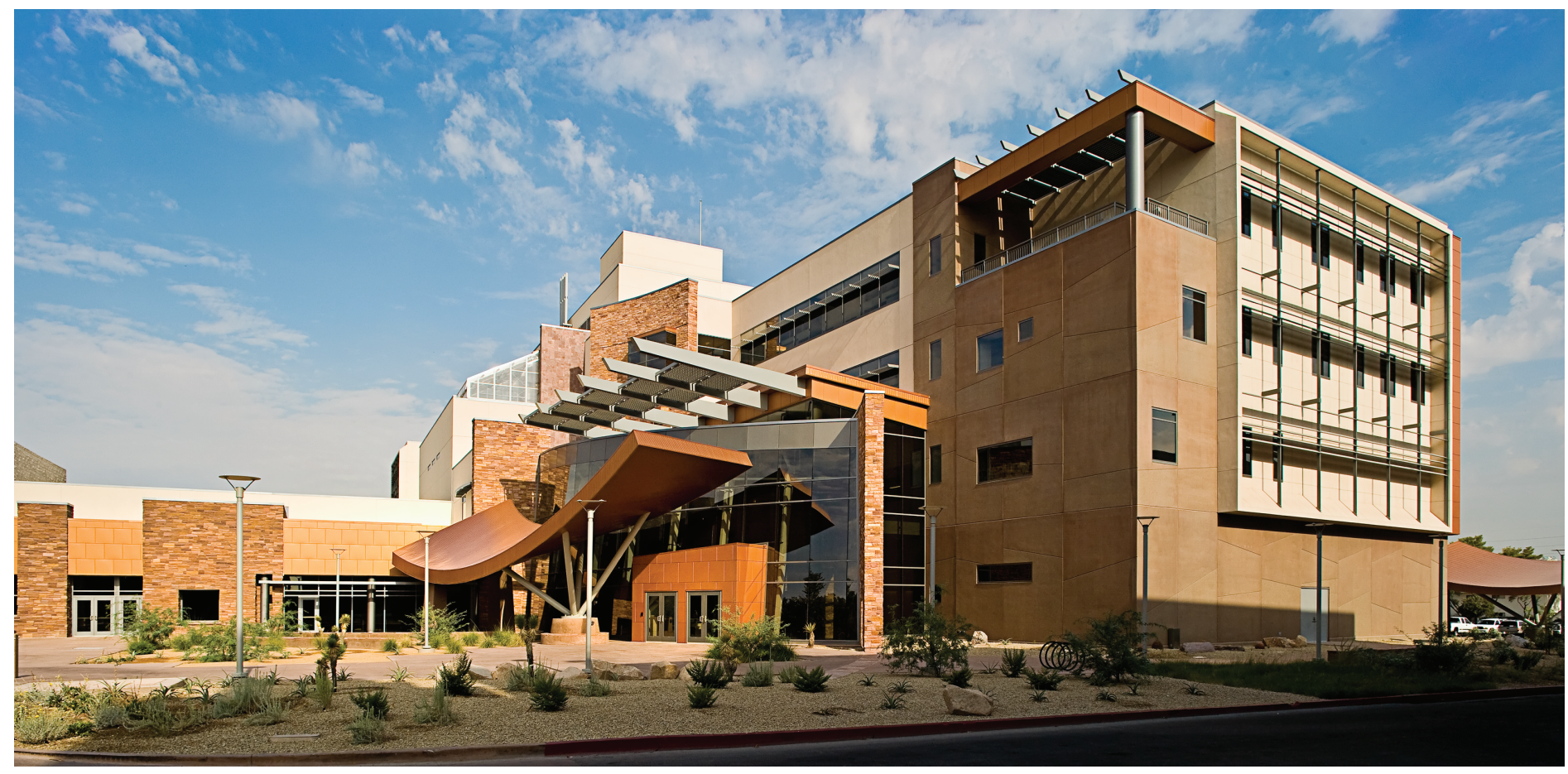

The Science and Engineering Building, located on the north side of the University of Nevada Las Vegas' campus, is a state-of-the-art facility designed for interdisciplinary research and education. It was recently instrumented for earthquake monitoring by the U.S. Geological Survey's National Strong Motion Project in collaboration with UNLV's Department of Civil and Environmental Engineering and Construction. 

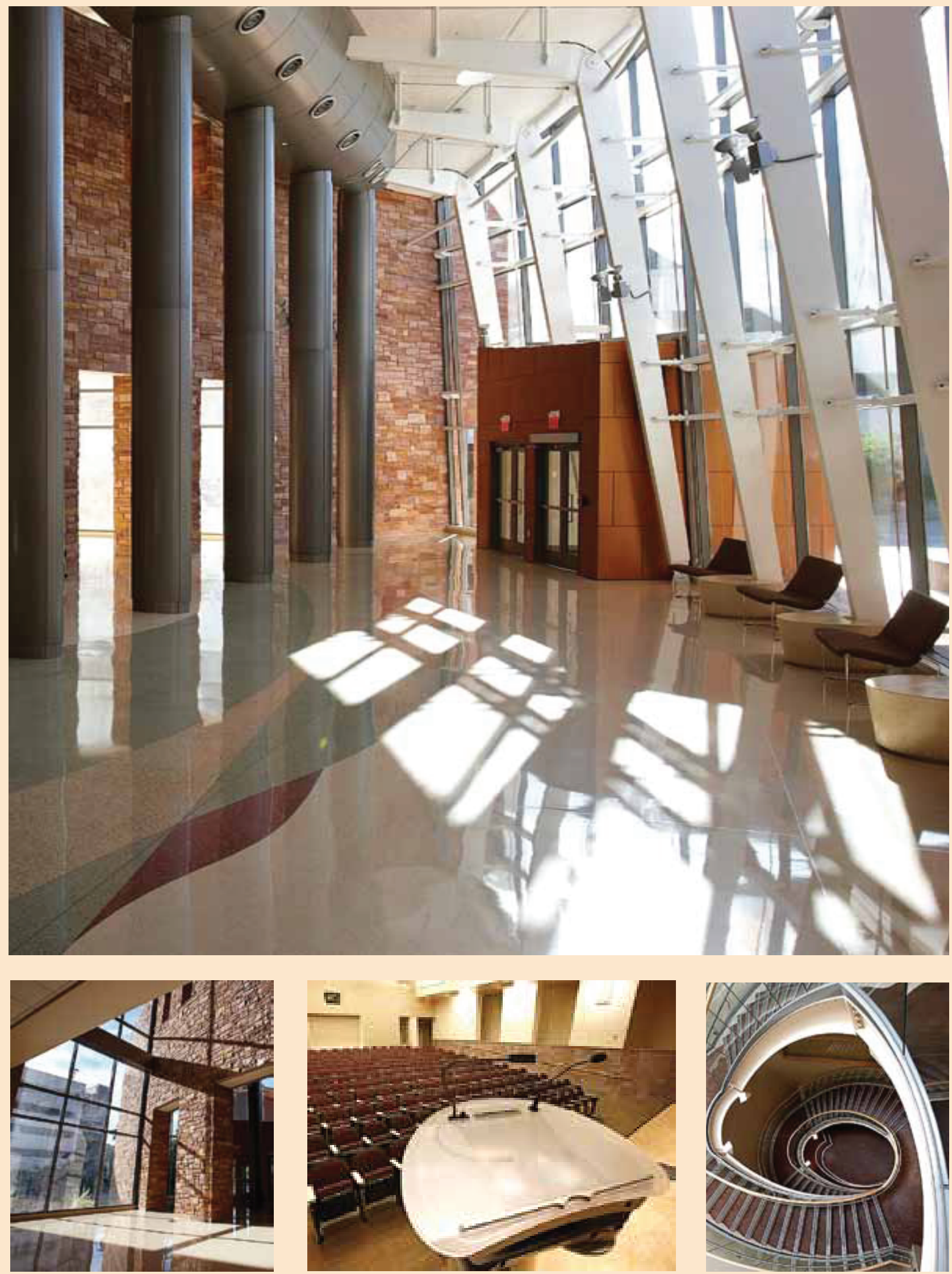

Photographs showing some details of the interior of the University of Nevada Las Vegas' Science and Engineering Building. High-performance glazing used in this award-winning environmentally friendly structure reduces solar-heat gain from the exterior, insulates the building from heat loss on the interior, and allows adequate levels of light to penetrate the building. As a result of the recent installation of a structural monitoring system, the building is also now at the forefront of seismic monitoring. 


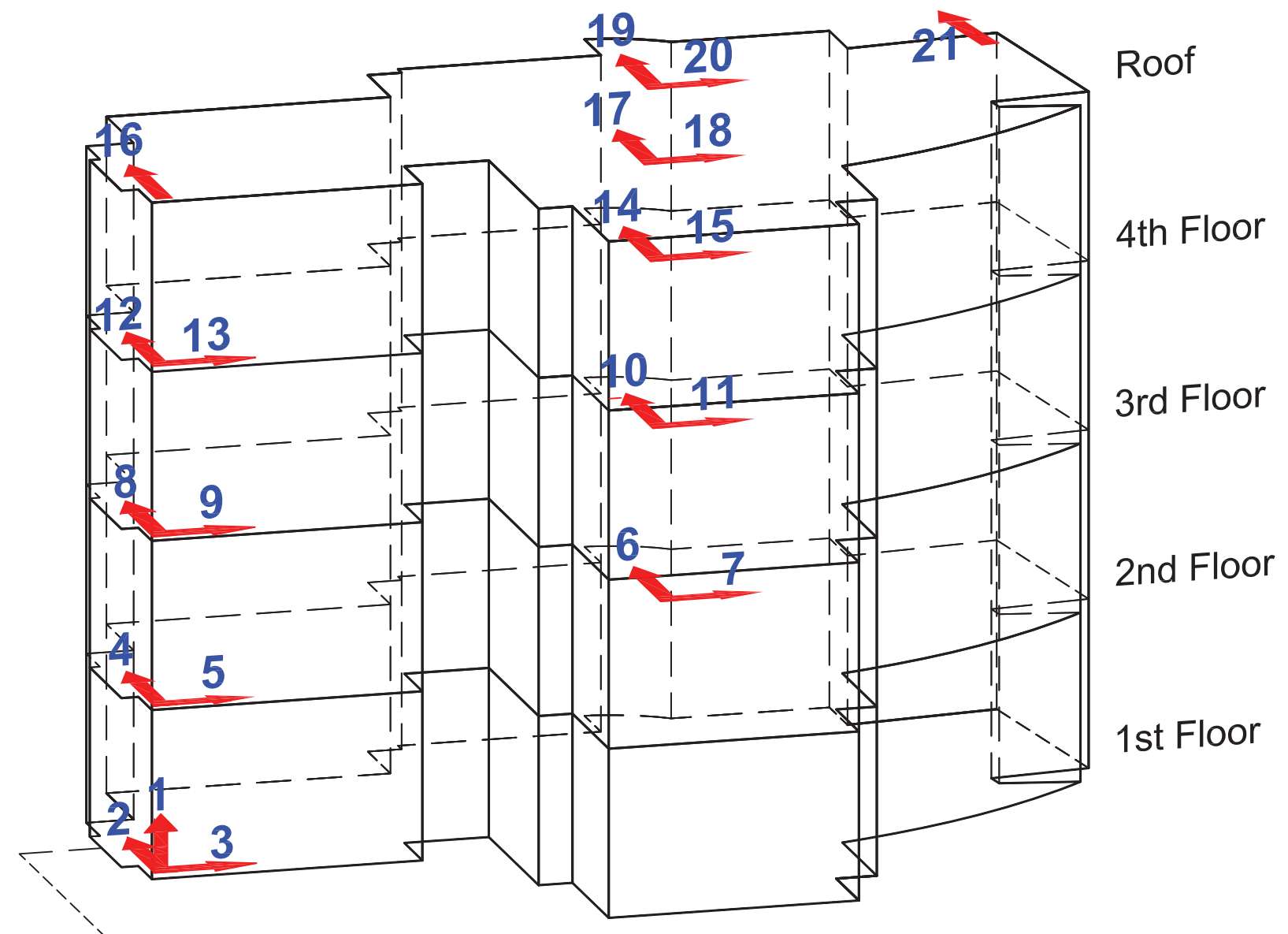

The LEED rating was awarded to this building because:

- The building has a satellite energy plant that provides heating and cooling,

- Recycled glass, steel, concrete, and wood were used for construction,

- High-performance glazing was used to reduce solar-heat gain from the exterior,

- Reductions in air conditioning needs due to incoming air becoming precooled through evaporation, and

- The building was designed to reduce water consumption by 42 percent.

This is the first LEED-certified building instrumented by NSMP and the only building in Las Vegas being monitored for earthquake shaking. This building is located in an area of moderate seismic hazard.
The intention of instrumenting this building is to see how buildings that are designed with the environment in mind hold up to the strong lateral forces generated by earthquakes. Building performance data obtained from the motion sensors installed in the building will be used to improve on environmentally responsible building designs.

When an earthquake is detected, the Science and Engineering Building's seismic-monitoring system rapidly acquires and transmits large amounts of data collected from sensors that have been permanently installed on each floor of the building. The data is then processed using modules integrated into an open-source structural-health monitoring (OpenSHM) software package, which extracts useful information from a large amount of measured data for the purpose of assessing the condition of a building both before and after an earthquake. This information can be used for a rapid building-safety assessment and to support decisions for necessary repairs, replacements, and other maintenance and rehabilitation measures.

The real-time data is also available to UNLV's faculty and engineering students through an onsite computer for studying and understanding the building's vibration characteristics and response during earthquakes.

\section{Advanced Sensing Technologies}

The UNLV Science and Engineering Building has an installed seismic array of 21 motion sensors. These advanced sensors are specifically located on each floor where the maximum building response during ground shaking is expected, which is mostly at the edges of the structure. Every story has at least two seismicmotion sensors oriented horizontally and in two orthogonal directions to detect building motion along the reference 


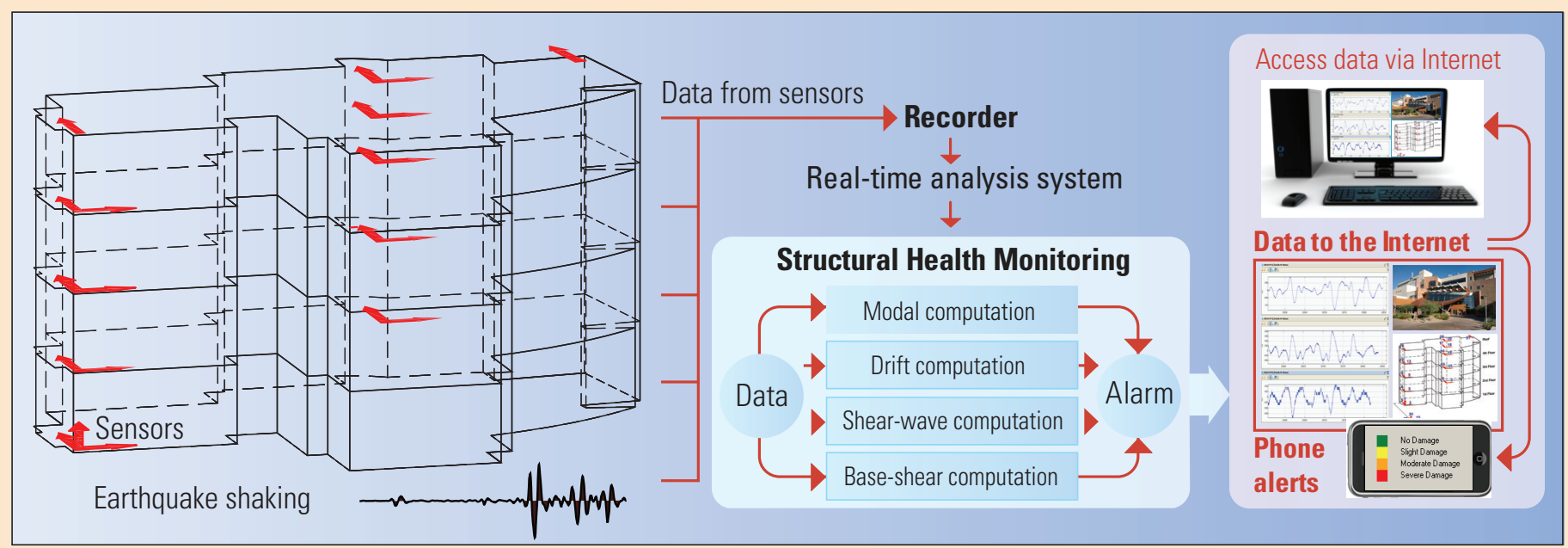

Flow chart showing the functioning of the real-time earthquake monitoring system installed in the University of Nevada Las Vegas' Science and Engineering Building. The system provides important information on the structural health of the building. After a significant earthquake, its realtime data analysis capabilities help to rapidly assess building safety and functionality.

east-west and north-south directions.

Floor rotation around the vertical axis can be computed from the recordings of two sensors pointing in the same direction but located at different points. The building also has a triaxial sensor installed on the first floor to record input motions in three orthogonal directions at this level. During an earthquake, the building's instrumentation system is designed to record and compute:

- The swaying and twisting of the building,

- The time it takes seismic waves to travel from the foundation to the roof, and

- How the frame of the building may have changed during the earthquake.

Another triaxial seismic-motion sensor located away from the building records ground shaking without any interference from the building to provide input for USGS ShakeMAPs (http://earthquake. usgs.gov/earthquakes/shakemap/), which depict ground motion and shaking intensity after significant earthquakes and give a visual representation of an earthquake's impact for emergency response.

\section{Structural-Health Monitoring and Damage Detection}

It is important to monitor the condition of one of UNLV's most important buildings in real time to be able to assess its structural integrity immediately after a major or catastrophic event.
Structural-health monitoring is achieved by implementation of an open-source onsite data analysis system. This innovative system provides information about how the building moves and distorts during shaking and about where possible damage likely occurred. Several independent algorithms check for variations in movements of the building frame and its vibration characteristics for changes in the travel time of seismic waves between foundation and roof and for exceedance of the building's seismic design capacity. In the aftermath of a disaster, such information can be used for a rapid assessment of building safety and for supporting decisions about necessary repairs, replacements, and other maintenance and rehabilitation measures. Recordings from structural-health monitoring systems are also crucial to both designing safer buildings and preventing loss of life. In particular they will help engineers to:

- Assess building safety immediately following a damaging earthquake,

- Understand how damage to structural and nonstructural components (such as equipment and pipes) occurs from strong shaking,

- Evaluate and improve earthquakeresistant design techniques, as well as methods for predicting the seismic performance of structures, and

- Improve earthquake-resistant design provisions of building codes.
More than 250 structures throughout the United States have been outfitted with seismic sensors by the USGS National Strong Motion Project (NSMP) to improve the overall understanding of earthquakes and their effects on the built environment. The instrumentation and monitoring of structures by NSMP is only one part of USGS efforts to protect people's lives and property from earthquake hazards in all of the Nation's seismically active regions.

Erol Kalkan ${ }^{1}$, Woody Savage ${ }^{2}$, Shahneam Reza ${ }^{1}$, Eric Knight ${ }^{2}$, and Ying Tian ${ }^{2}$

${ }^{1}$ U.S. Geological Survey

${ }^{2}$ University of Nevada, Las Vegas

Edited by James W. Hendley II Graphic design by Vivian Nguyen

COOPERATING ORGANIZATION

University of Nevada, Las Vegas

For more information, contact:

Earthquake Science Center U.S. Geological Survey

Menlo Park, CA 94025

http://earthquake.usgs.gov/

Earthquake Information Hotline: (650) 329-4085

This Fact Sheet and any updates to it are available online at

http://pubs.usgs.gov/fs/2013/3022/ 